\title{
WAVE LOADS AND STABILITY OF NEW FOUNDATION STRUCTURE FOR OFFSHORE WIND TURBINES MADE OF OCEAN BRICK SYSTEM (OBS)
}

\author{
S. Pfoertner ${ }^{1}$, H. Oumeraci ${ }^{1}$, M. Kudella ${ }^{2}$, A. Kortenhaus ${ }^{1}$
}

\begin{abstract}
The Ocean Brick System (OBS) is a modular system consisting of hollow concrete precast blocs (10m x 10m x 10m) piled up like cubes and interconnected to create a stiff, light and strong structure which can be used for artificial islands, artificial reefs, elevation of vulnerable low lands, deep water ports, breakwaters and foundation of offshore wind turbines. The paper focuses on the experimental results on the wave loading and the stability of the OBS used as a foundation of the support structure of offshore wind turbines. Diagrams for the prediction of total horizontal forces, vertical forces and overturning moments induced by irregular waves on the OB-structure are derived and verified through additional stability tests and stability analysis.
\end{abstract}

Keywords: modular structure, offshore wind turbine, total wave loads, sliding/overturning stability, rubble foundation

\section{INTRODUCTION}

To meet the challenges associated with climate changes in coastal zones, innovative concepts are not only urgently needed for coastal defences (Oumeraci, 2009), but also for offshore structures, particularly for those associated with the use of renewable energy in marine zones.

The Ocean Brick System (OBS) is a modular system which consists of hollow concrete precast blocs $(10 \mathrm{~m} \times 10 \mathrm{~m} \times 10 \mathrm{~m})$ piled up like cubes and interconnected to create a stiff, light and strong structure which can be used for artificial islands, artificial reefs, elevation of vulnerable low lands, deep water ports, breakwaters and foundation of offshore wind turbines. The entire structure or components can be built in a dry dock and then floated and towed to the planned construction site. OBS Ltd. has commissioned the Leichtweiss-Institute to conduct systematic hydraulic model studies on the wave loading and the hydraulic performance of different types of structures made of Ocean Bricks such as foundation of offshore wind turbines, harbour breakwaters and quay walls.

The primary objective of these studies is to understand and predict the hydraulic functioning (e.g. wave transmission, reflection, dissipation, overtopping), the total wave loads and stability of the OBS used for a wide range of coastal, harbour and offshore structures, including artificial islands. A further objective is to identify the limitations of the OBS with respect to both hydraulic performance and stability against wave loads, but also to test possible solutions for reducing these limitations, (e.g. increase of stability, decrease of wave transmission).

The first study on the wave loading and the stability of an OB-made foundation structure has now been completed (Oumeraci et al, 2008). Therefore, the paper will focus on the results of this first study only. In a brief section, the model set-up is first described, including the observation and measuring techniques deployed and the testing programme. Focus is put on the description of a special transducer system which has been especially developed for the measurement of the total wave loads on the fully submerged large structure.

In the major part of the paper the experimental results related to the total horizontal and vertical wave forces, including the resulting overturning moments, are analysed and diagrams are derived for the prediction of maximum wave loads of the submerged structure subject to irregular waves. Additional stability tests to verify the proposed diagrams have also been conducted. Example calculations for given design wave conditions are then provided to illustrate the application of the proposed diagrams for wave load prediction.

Finally, recommendations are given for the design of the rubble foundation of the OB-structure which are based on the results of preliminary model tests and an extensive literature study

\footnotetext{
${ }^{1}$ Leichtweiss-Institute for Hydraulic Engineering and Water Resources, Technische Universitaet Braunschweig, Beethovenstr. 51a, D-38106 Braunschweig, Germany

${ }^{2}$ Coastal Research Centre (FZK) of Leibniz University Hannover and TU Braunschweig, Merkurstr. 11, D-30419 Hannover, Germany
} 


\section{EXPERIMENTAL SET-UP, TESTING PROGRAMME AND PROCEDURE}

\section{OBS model description}

The prototype dimensions of the OBS foundation structure tested are $40 \mathrm{~m} \times 40 \mathrm{~m} \times 10 \mathrm{~m}$. The geometric scale of the OBS-model on a rubble foundation ( $2 \mathrm{~m}$ thick in prototype) with and without a monopile is 1:50 (Fig. 1).

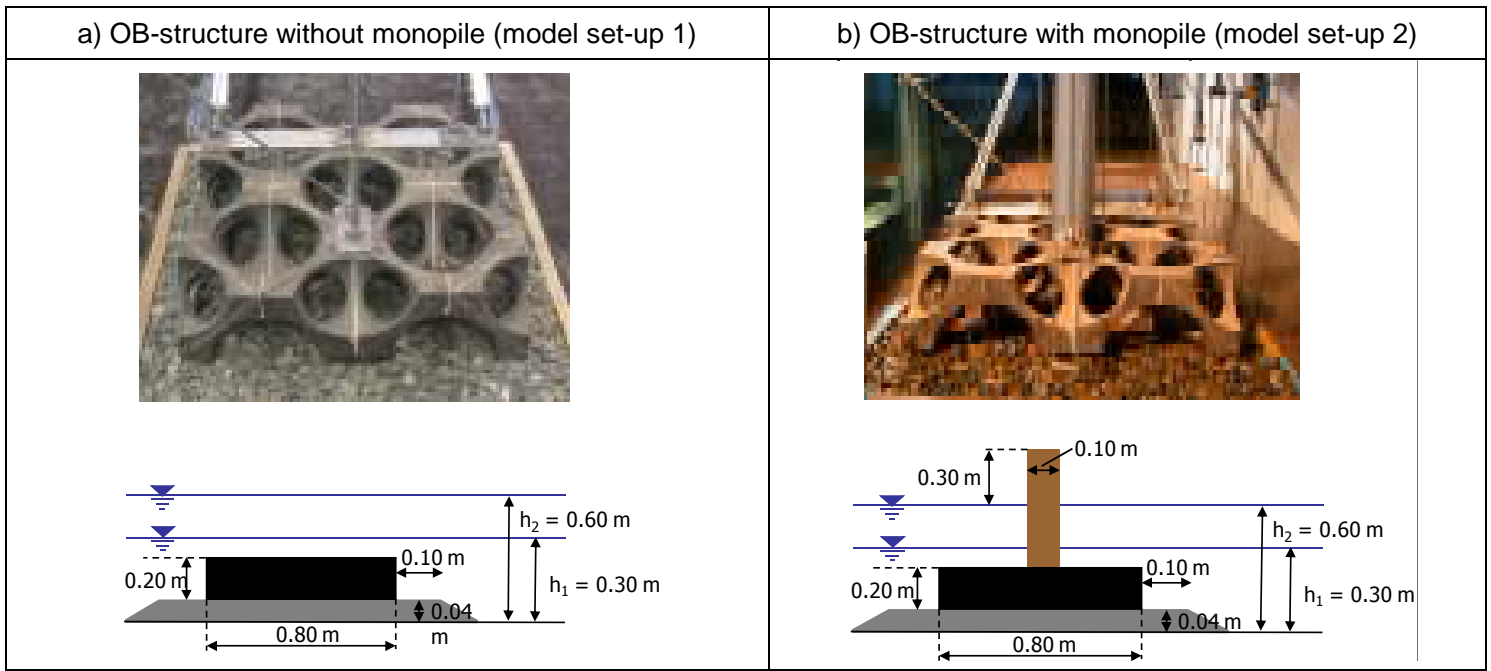

Figure 1. OBS used as a foundation structure for offshore wind turbine (model scale 1:50)

The model with two different set-ups was built in a two meter wide wave flume (Fig. 2). The wave flume is about $90 \mathrm{~m}$ long and $1.25 \mathrm{~m}$ deep. The piston-type wave maker, equipped with an active wave absorption, can generate regular and irregular waves as well as solitary waves up to $0.30 \mathrm{~m}$ high.

\section{Measuring and observation techniques}

A total of 16 resistance-type wave gauges were installed to measure water surface elevations in front, at and behind the structure, including two gauge arrays for the wave reflection analysis (Figs. 2 and 3). To measure the flow velocity near the bed, two Acoustic Doppler Velocimeters (ADV) were placed at the lateral sides of the OBS-model (indicated as current meters (CM) in Fig. 2).

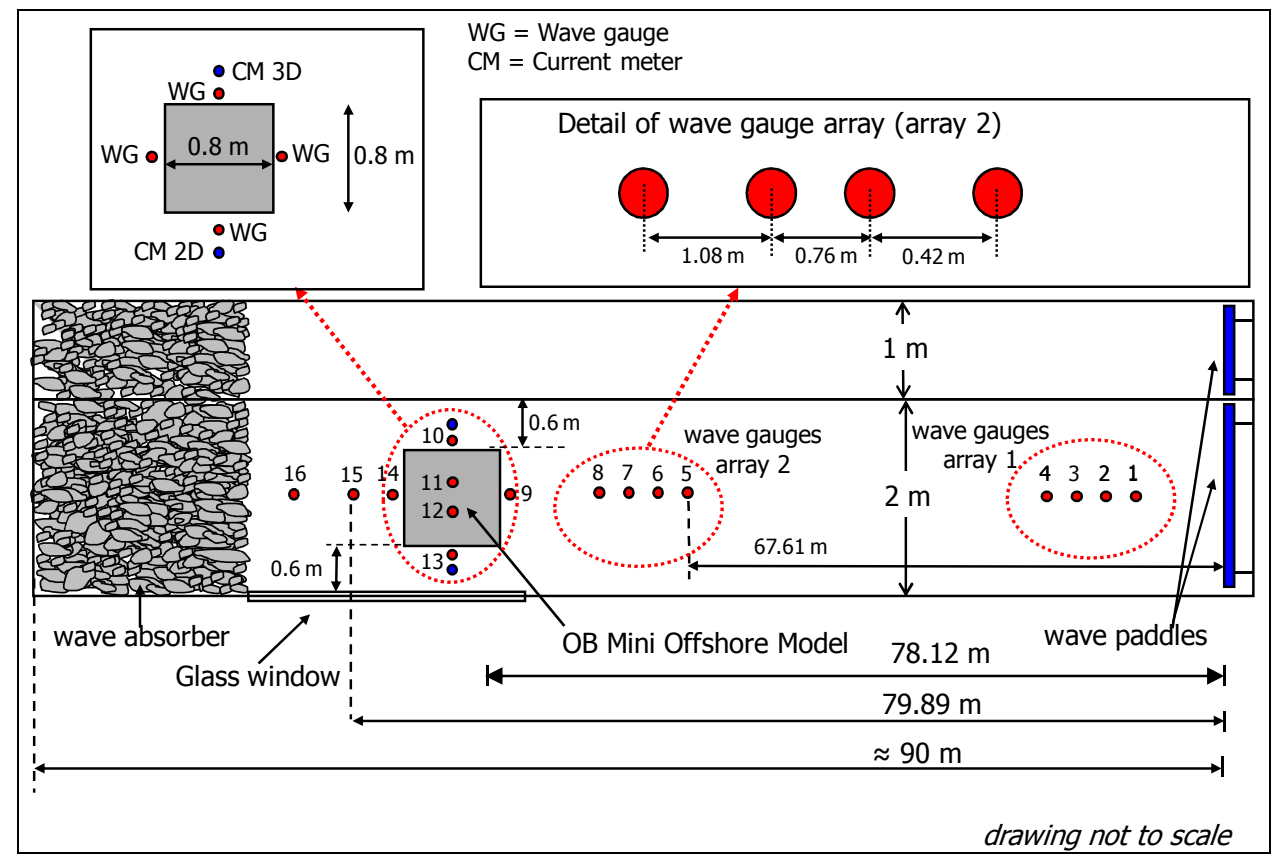

Figure 2. Model set-up in the $2 \mathrm{~m}$-wide wave flume at LWI (plan view) 


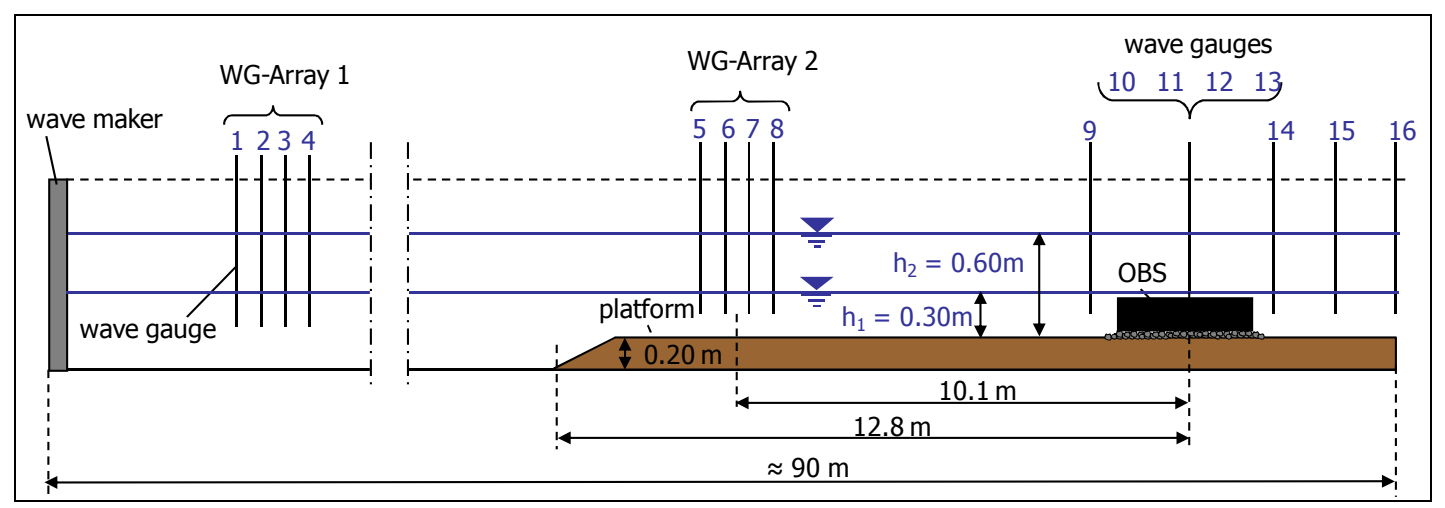

Figure 3. Position of the wave gauges and the OBS-model in the wave flume (cross section)

To measure the total horizontal and vertical forces and the resulting overturning moment induced by the waves on the OBS model a new load transducer system was especially developed and constructed for this study.

The OBS-model was attached to six thin beams, building a statically determinate system. These beams were fixed to cross beams installed over the top of the $2 \mathrm{~m}$ wide flume. At the end of every beam a force transducer was installed (Fig. 4). Using the recorded forces at the six load transducers, an algorithm was developed to provide directly the total horizontal forces, the total vertical forces, and the resulting overturning moment around any pre-defined point.

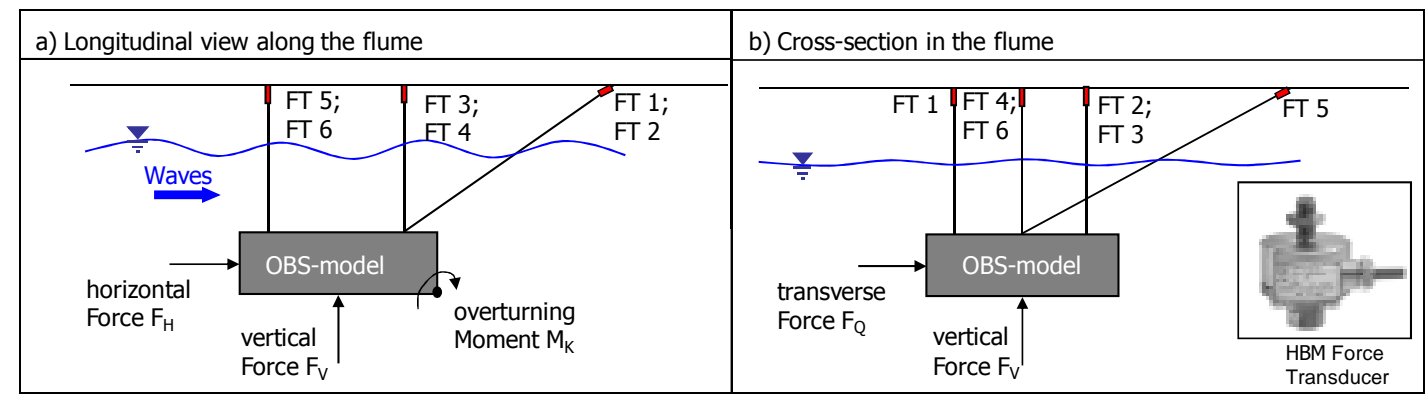

Figure 4. Total wave load transducer and OBS model

Before starting the hydraulic model tests, the transducer system was systematically calibrated using pre-defined time dependent loads. More details on the calibration procedure and on the transducer itself are given in Oumeraci et al (2008). Two video cameras were used to record the hydraulic processes in front, at and behind the model structure.

Remark:

During the tests using the wave load transducers in Fig. 4, a more sophisticated and less intrusive wave load transducer was developed and constructed, so that the most important tests with respect to wave loads could be repeated and compared to the tests using the transducer in Fig. 4. A very good agreement between the two transducers was achieved for the horizontal and vertical wave forces as well as for the resulting overturning moments.

\section{Test programme and testing procedure}

Irregular waves (JONSWAP-spectrum) were used with a significant wave height $\mathrm{Hs}=0.05-0.23 \mathrm{~m}$ (Prototype $\mathrm{Hs}=2.5-12.5 \mathrm{~m}$ ) and peak period $\mathrm{Tp}=1.0-2.8 \mathrm{~s}$ (Prototype $\mathrm{Tp}=7-19 \mathrm{~s}$ ). Moreover, solitary waves were used to get a better insight into the underlying processes, and thus to check the reliability of the irregular wave tests. In this paper, however, only the results of the irregular wave tests will be addressed. Further details are given in the final report by Oumeraci et al (2008). Two water depths were tested: $\mathrm{h}=0.30 \mathrm{~m}$ and $\mathrm{h}=0.60 \mathrm{~m}$ (Prototype $\mathrm{h}=15 \mathrm{~m}$ and $30 \mathrm{~m}$ ). Each test was repeated at least twice.

Three model configurations were tested: (a) wave loads on OBS-model without monopile, (b) wave loads with monopile, (c) stability of rubble foundation. Tests with configuration (b) were required to check the additional wave loads by introducing a monopile in the OBS-model (see Fig. 1a,b). The effect of the monopile on the total wave loads on the OBS-model was found to be in the range of the 
uncertainties of the measurements and the stochastic variability, so that the results of these tests will not be addressed here. However, details can be found in Oumeraci et al (2008). The tests with configuration (c) were conducted with the OBS-model lying directly on the rubble foundation (Fig. 1a), so that the total wave loads cannot be measured. At least 600 waves were generated for each test.

Since the wave loads in seaward direction were found to be only slightly smaller than the wave loads in shoreward direction, the latter only are considered in this paper.

\section{HORIZONTAL WAVE FORCES}

The measured maximum horizontal wave forces $\mathrm{F}_{\mathrm{h} \text {,max }}$ are given in Fig. 5 as a function of the maximum wave height, showing that $\mathrm{F}_{\mathrm{h} \text {,max }}$ is higher for water depth $\mathrm{h}=0.30 \mathrm{~m}$ than for water depth $\mathrm{h}=0.60 \mathrm{~m}$. Surprisingly, no measurement or formulae for the wave load on such large complex porous submerged structures could be found in the literature for comparison.

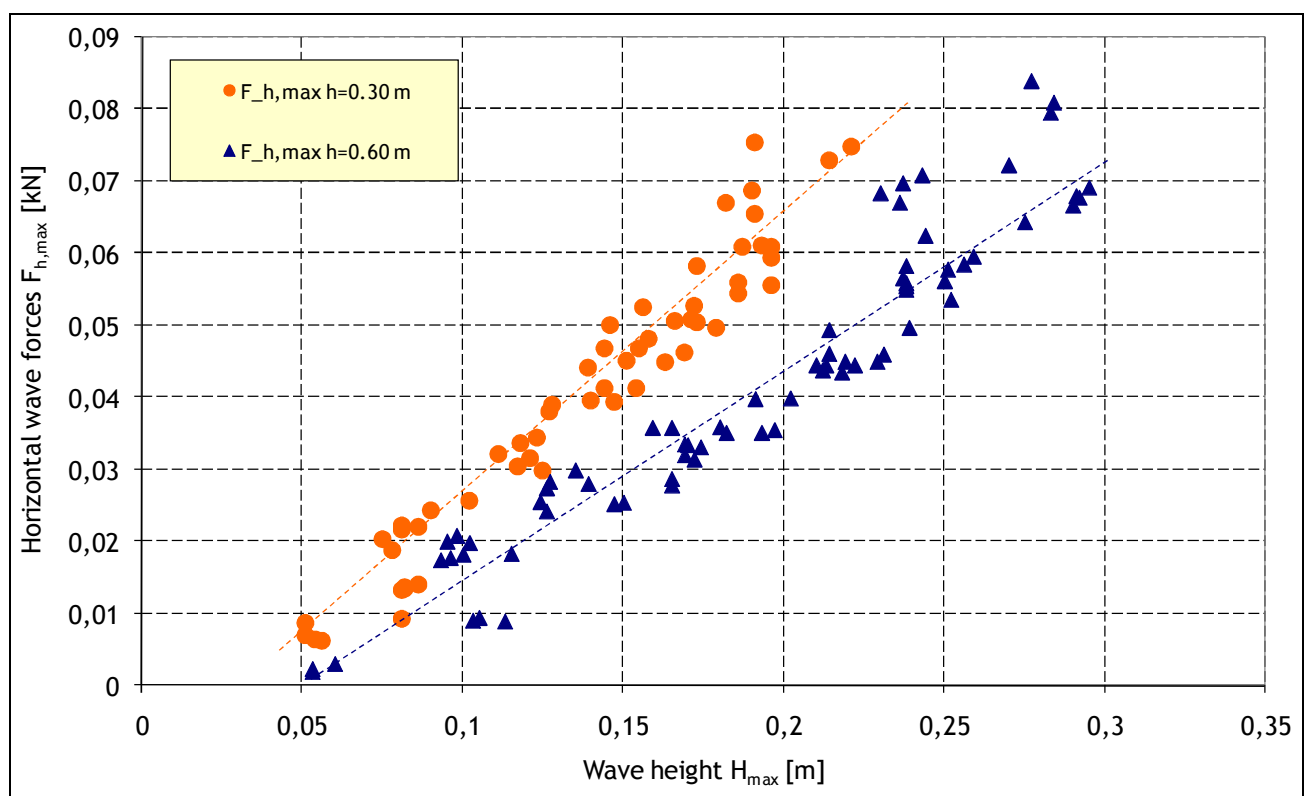

Figure 5. Measured maximum horizontal wave forces on the OBS-model without monopile (see Fig. 1a)

Therefore, to check the order of magnitude of the measured forces, a rough approximation using linear wave theory was required. The effect of the porosity was accounted for by introducing a correction for the contact area of wave pressure at the OBS-model. As expected, the approximate horizontal wave forces are generally lower than the measured values. As shown exemplarily for water depth $\mathrm{h}=0.30 \mathrm{~m}$, this is more pronounced for higher waves due to the non-linearity of the latter (Fig. 6).

The effect of the nonlinearity of the waves was accounted for by adjusting the calculated increase rate (see slope angle $\alpha_{t}$ and $\alpha_{m}$ in Fig. 6, exemplarily for $h=0.30 \mathrm{~m}$ ). 


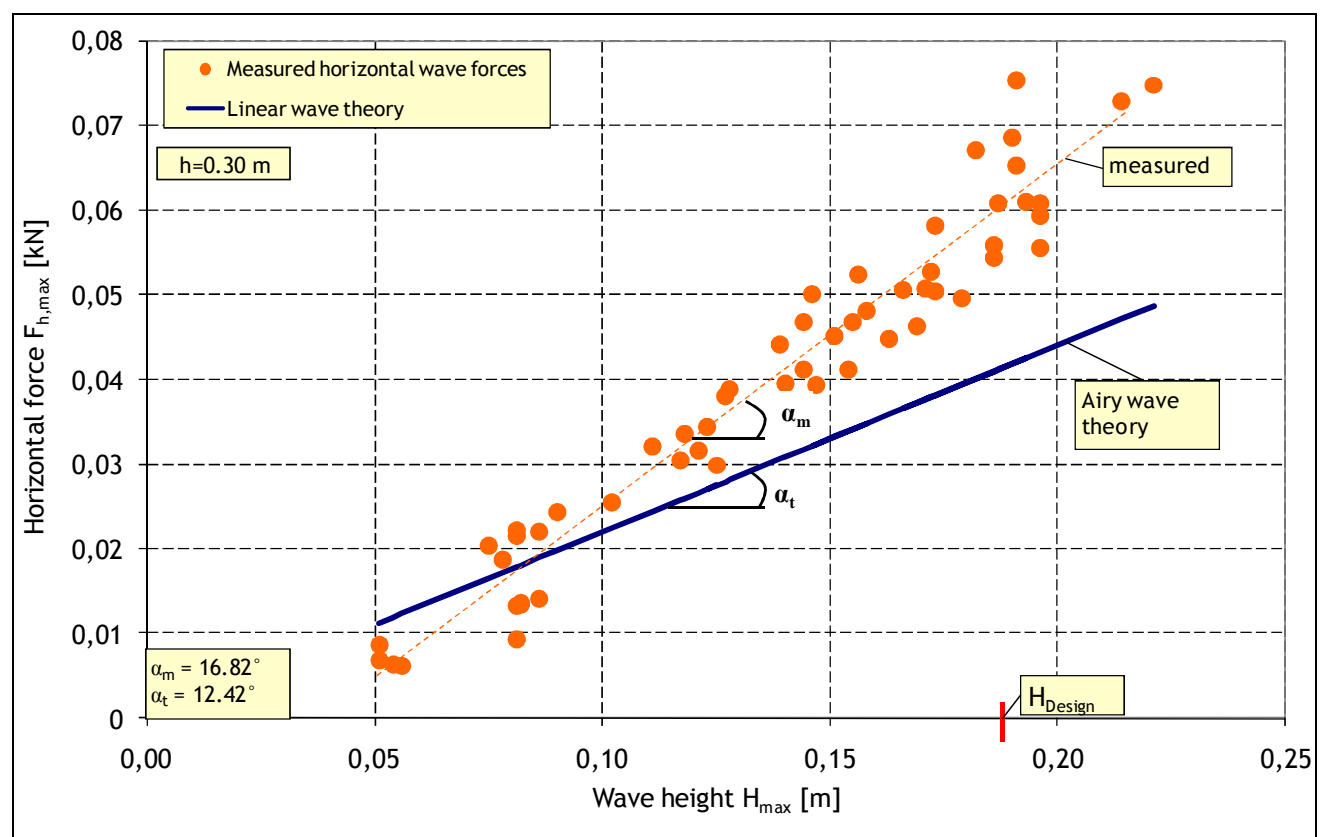

Figure 6. Comparison of measured and calculated wave forces for water depth $h=0.30 \mathrm{~m}$

Moreover, the effect of the relative water depth $(\mathrm{h} / \mathrm{L})$ on the measured wave forces was also found to be important and was therefore accounted for by introducing the wave pressure factor $\mathrm{K}_{\mathrm{p}}$ :

$$
K_{P}(h / L)=\frac{\cosh \left(\frac{2 \pi}{L}(z+h)\right)}{\cosh \left(\frac{2 \pi}{L} h\right)}
$$

Using the wave pressure factor $\mathrm{K}_{\mathrm{p}}$ and the adjustment of the increase rate, the results for the tested water depths are plotted in Fig. 7 for prototype conditions, showing that the calculated values $\mathrm{F}_{\mathrm{h}, \text { calc }}$ may overestimate or underestimate the measured forces induced by irregular waves by a range up to $30 \%$ (lower bound) and $27 \%$ (upper bound), respectively.

The prototype design wave height $\mathrm{H}_{\mathrm{D}}=\mathrm{H}_{\max }$ for water depths $\mathrm{h}=15 \mathrm{~m}$ and $\mathrm{h}=30 \mathrm{~m}$ adopted in this study are also indicated in Fig. 7 (see example applications later).

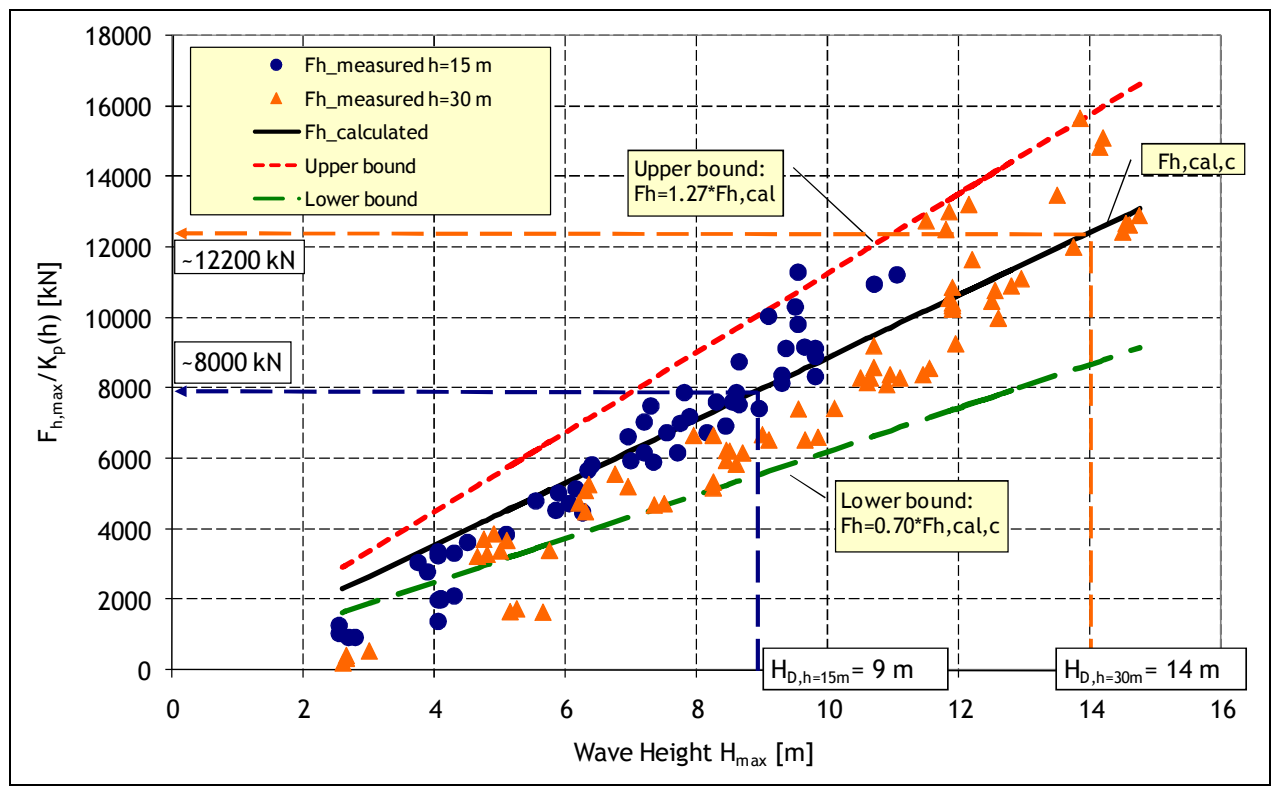

Figure 7. Comparison of calculated and measured horizontal wave forces (prototype scale) 
$\underline{\text { Remark: }}$

Since the OBS-structure is large as compared to the wave length, diffraction effects are important. Using wave theory and dimensional analysis, the most dominant influencing parameters for the range of wave conditions tested were found to be (i) relative water depth $\mathrm{h} / \mathrm{L}$ (dispersion parameter), (ii) wave steepness $\mathrm{H} / \mathrm{L}$ (nonlinearity parameter), (iii) diffraction parameter $2 \pi \mathrm{a} / \mathrm{L}$ (where $\mathrm{a}$ is a characteristic linear dimension of the OBS-structure) and (iv) relative water depth (h/a). The effect of each of these parameters on the total wave loads on the OBS-structure is first analysed separately and in combination to better assess their relative importance. In Fig. 8 the effect of the diffraction parameter $2 \pi \mathrm{a} / \mathrm{L}$ on the dimensionless horizontal wave force is exemplarily shown for relative depth $\mathrm{h} / \mathrm{a}=6$ and $\mathrm{h} / \mathrm{a}=12$ to illustrate the relative importance of both parameters on the wave load.

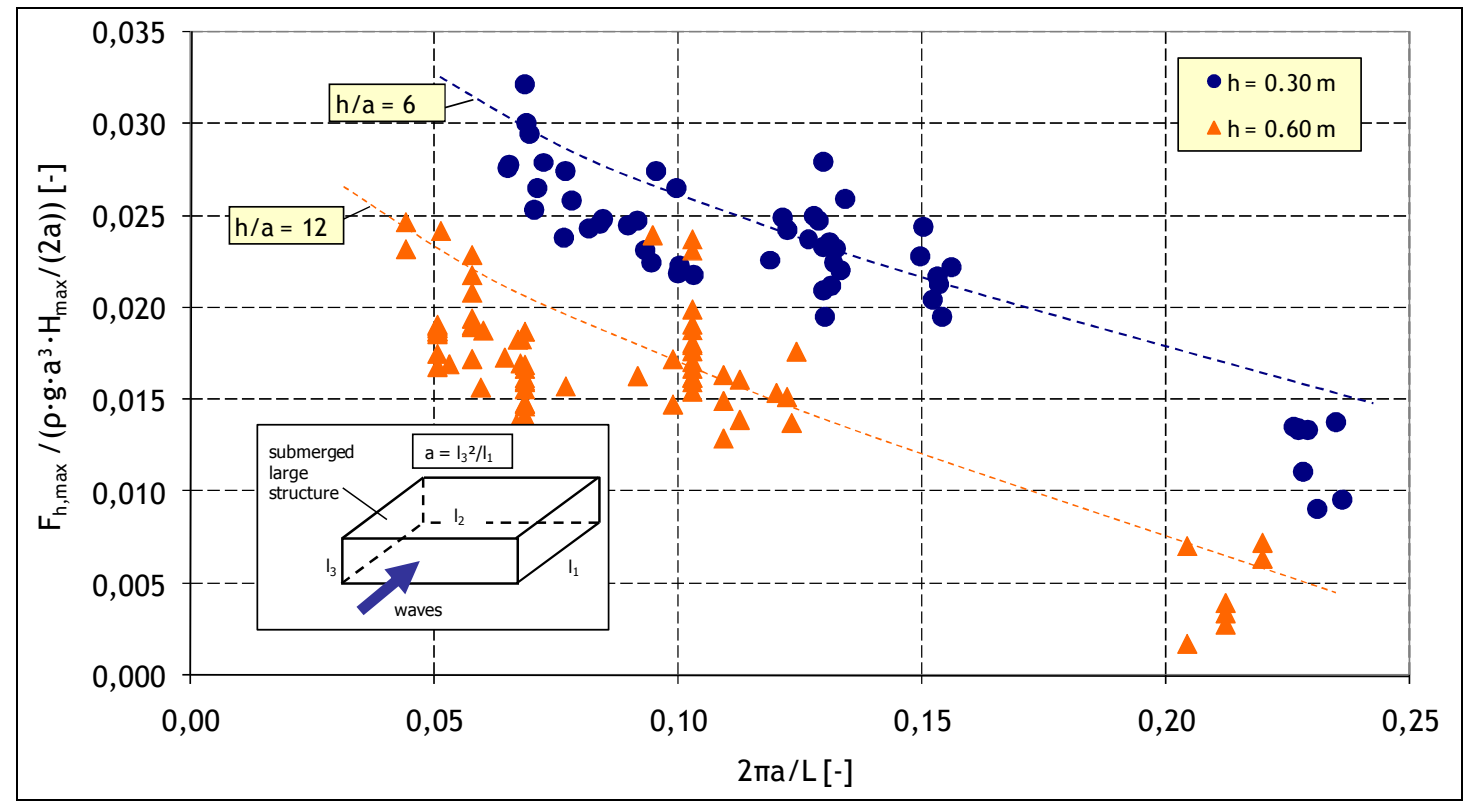

Figure 8. Effect of diffraction parameter $2 \pi \mathrm{a} / \mathrm{L}$ and relative water depth $\mathrm{h} / \mathrm{a}$ on dimensionless horizontal wave force

\section{VERTICAL WAVE FORCES}

The approach used for the analysis of vertical wave forces is similar to the approach described above for the horizontal wave forces. Considering the effect of the relative water depth $\mathrm{h} / \mathrm{L}$ (see Eq. 1) and the non-linearity of the waves, the vertical wave forces calculated using linear wave theory were corrected for both tested water depths $h=15 \mathrm{~m}$ and $\mathrm{h}=30 \mathrm{~m}$. As a result the prediction diagram in Fig. 9 is obtained for the vertical wave forces at prototype scale in a similar way as the diagrams for the horizontal wave forces in Fig. 7.

The corrected calculated values $\mathrm{F}_{\mathrm{v}, \mathrm{calc}}$ may overestimate or underestimate the measured irregular wave forces by a range up to $51 \%$ (lower bound) and $55 \%$ (upper bound), respectively. The prototype design wave height $\mathrm{H}_{\mathrm{D}}=\mathrm{H}_{\max }$ for both water depths $\mathrm{h}=15 \mathrm{~m}$ and $\mathrm{h}=30 \mathrm{~m}$ adopted in this study are also indicated in Fig. 9 (see example application later). 


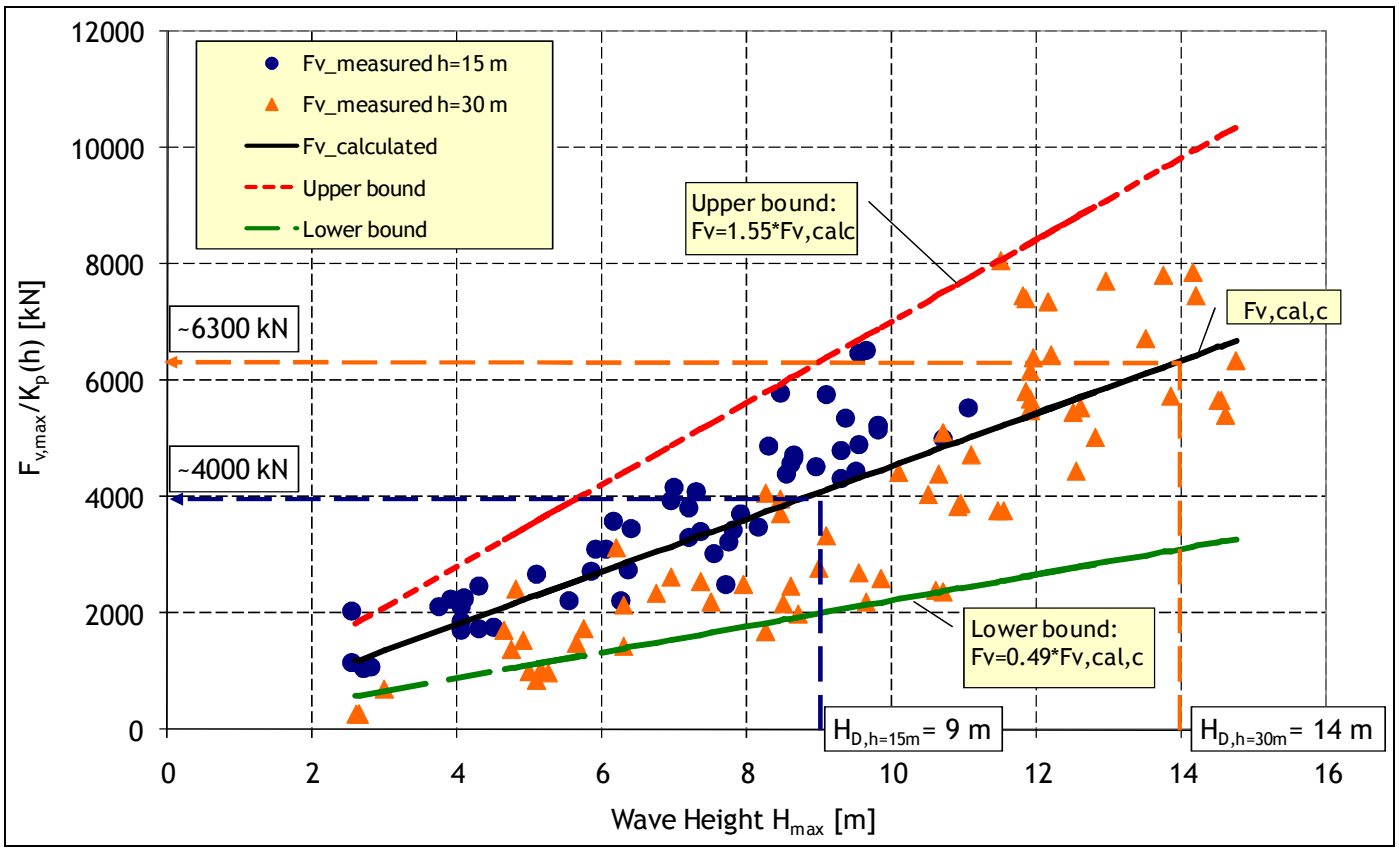

Figure 9. Comparison of calculated and measured vertical wave forces (prototype scale)

\section{OVERTURNING MOMENTS}

The overturning moments which are induced around the rear edge of the structure (see Fig. 4a) by the horizontal and vertical wave forces were analysed in a similar way to the horizontal and vertical wave forces described in the previous sections. As a result, prediction diagrams were obtained for both tested water depths $\mathrm{h}=15 \mathrm{~m}$ (Fig. 10a) and $\mathrm{h}=30 \mathrm{~m}$ (Fig. 10b), showing that:

(i) For water depth $\mathrm{h}=15 \mathrm{~m}$ the corrected calculated values $\mathrm{M}_{0, \text { calc }}$ may overestimate or underestimate the measured moment by a range up to $20 \%$ (lower bound) and 27\% (upper bound), respectively.

(ii) For water depth $\mathrm{h}=30 \mathrm{~m}$ the corrected calculated values $\mathrm{M}_{0 \text {,calc }}$ may overestimate or underestimate the measured moments by a range up to 35\% (lower bound) and $40 \%$ (upper bound), respectively.

\section{Example application for wave loads}

For $\mathrm{h}=15 \mathrm{~m}, \mathrm{H}_{\max }=9 \mathrm{~m}, \mathrm{~T}_{\mathrm{p}}=11.3 \mathrm{~s}$ and using the diagrams in Figures 7-9, the mean values for the horizontal wave forces $F_{h, \text { max }}$, the vertical wave forces $F_{v, \text { max }}$ and the resulting overturning moment around the heel of an OB-structure $40 \mathrm{~m} \times 40 \mathrm{~m} \times 10 \mathrm{~m}$ are obtained, including the upper and lower bound (Table 1):

\begin{tabular}{|c|c|c|c|}
\hline & $\begin{array}{l}\text { horizontal wave forces } \\
{[\mathrm{kN}]}\end{array}$ & $\begin{array}{l}\text { vertical wave forces } \\
{[\mathrm{kN}]}\end{array}$ & $\begin{array}{c}\text { overturning } \\
\text { moment }[\mathrm{kNm}]\end{array}$ \\
\hline lower bound & 4648 & 1627 & 59760 \\
\hline mean & 6640 & 3320 & 74700 \\
\hline upper bound & 8433 & 5146 & 94700 \\
\hline
\end{tabular}

The large scatter is essentially due to the high stochastic variability of the irregular wave loads. Of course it is up to the designer to select the appropriate characteristic load values for the actual design case, depending on the specific function of the structure and the consequences of possible failure. Ideally, a reliability and risk-based design would be the most appropriate choice for the detailed design stage, including more focused hydraulic model testing by accounting for the specific conditions of the case study. For preliminary design it would be more appropriate to use the upper bound values in order to avoid any sliding or tilting of the structure. 


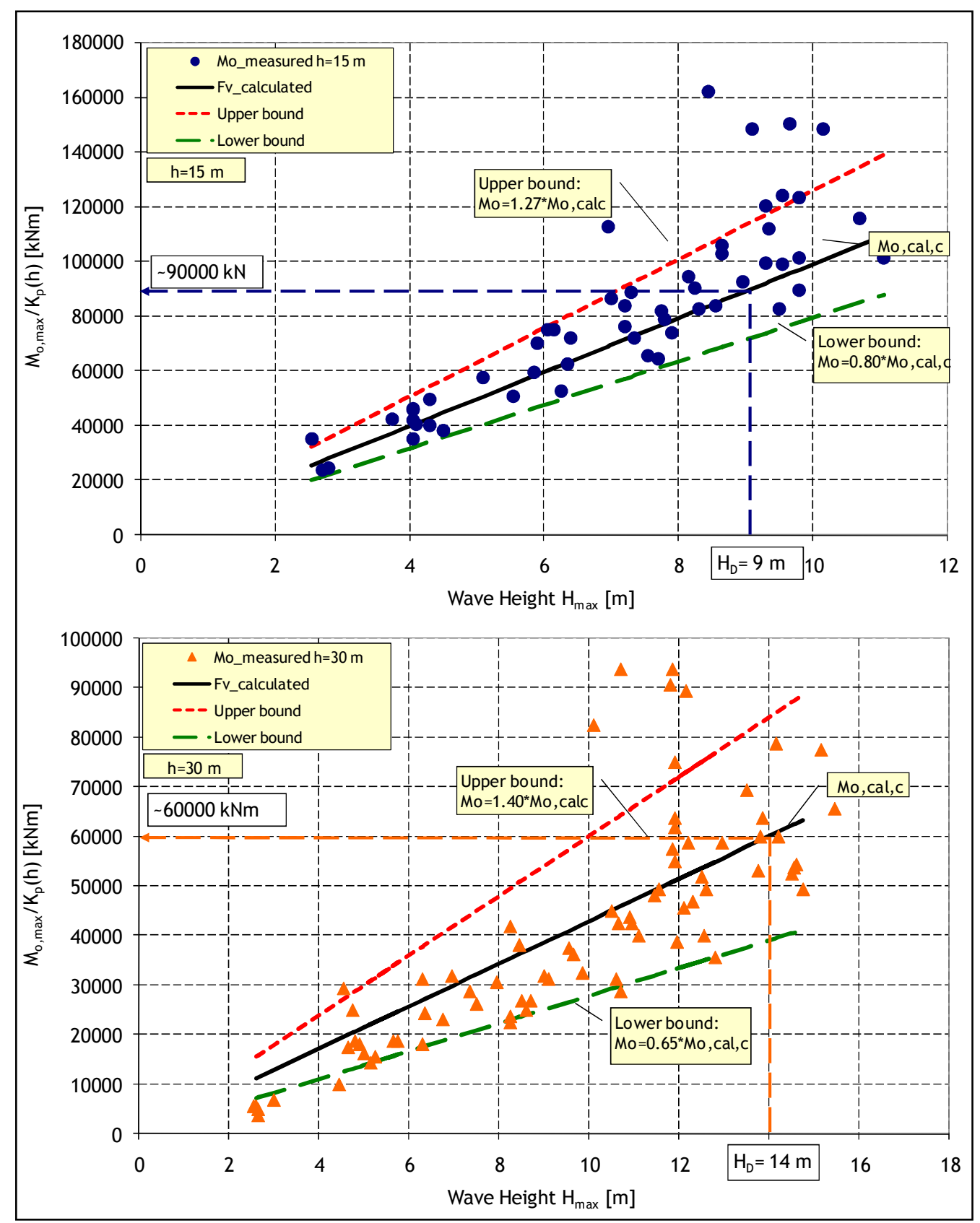

Figure 10. Comparison of calculated and measured overturning moments (prototype scale)

\section{STABILITY TESTS/STABILITY ANALYSIS OF THE OBS STRUCTURE}

To determine the static friction coefficient $\mathrm{f}_{\mathrm{R}}$ between the OBS-structure and the rubble foundation, detailed sliding tests (Fig. 11) were performed showing that $\mathrm{f}_{\mathrm{R}} \approx 0.6$ can be applied for the calculation of the sliding safety coefficient $\mu_{\mathrm{d}}$ (Oumeraci et al, 2008):

$$
\mu_{d}=f_{R} \cdot \frac{W^{\prime}-F_{v, \text { max }}}{F_{h, \text { max }}}
$$

where $\mathrm{W}^{\prime}$ is the weight of the OBS-structure under buoyancy $\left(\mathrm{W}^{\prime}=17363.7 \mathrm{kN}\right), \mathrm{F}_{\mathrm{h} \text {,max }}$ and $\mathrm{F}_{\mathrm{v} \text { max }}$ are the maximum horizontal and vertical wave forces, respectively. 


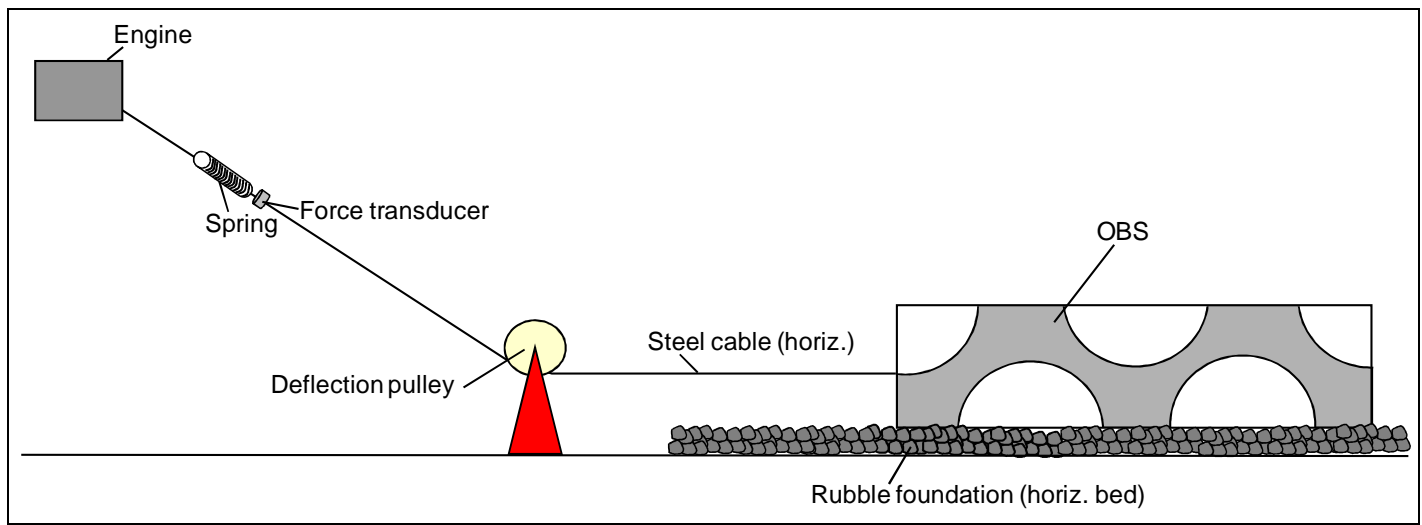

Figure 11. Sliding tests for the determination of the friction coefficient

Additional hydraulic model tests were performed in the wave flume by increasing the incident waves incrementally until the OBS-structure starts to slide. Although it was difficult to identify accurately the actual inception of motion of the OBS-structure during the tests, the following tentative conclusions may be drawn from the results of these tests and the stability analyses of the OBS-structure against sliding and overturning:

(i) Stability against overturning

The OBS structure, even by including the wave forces and the wave loads on the monopile, appeared to be stable enough against overturning for both water depths $(\mathrm{h}=15 \mathrm{~m}$ and $\mathrm{h}=30 \mathrm{~m})$ and design wave conditions $\left(H_{\max }=9 \mathrm{~m}\right.$ and $\mathrm{T}_{\mathrm{p}}=11.3 \mathrm{~s}$ for $\mathrm{h}=15 \mathrm{~m}$ and $\mathrm{H}_{\max }=14 \mathrm{~m}$ and $\mathrm{T}_{\mathrm{p}}=17.7 \mathrm{~s}$ for $\left.\mathrm{h}=30 \mathrm{~m}\right)$.

(ii) Stability against sliding

The results of the sliding stability analysis suggest that even without considering the additional effect of the wind loads, the OBS structure itself may slide for both considered water depths $(\mathrm{h}=15 \mathrm{~m}$ and $\mathrm{h}=30 \mathrm{~m})$ and the associated design wave conditions $\left(\mathrm{H}_{\max }=9 \mathrm{~m}\right.$ and $\mathrm{T}_{\mathrm{p}}=11.3 \mathrm{~s}$ for $\mathrm{h}=15 \mathrm{~m}$ and $\mathrm{H}_{\max }=14 \mathrm{~m}$ and $\mathrm{T}_{\mathrm{p}}=17.7 \mathrm{~s}$ for $\left.\mathrm{h}=30 \mathrm{~m}\right)$. In both cases countermeasures to enhance the safety against sliding might be required (e.g. increasing the size of the OB-structure to $50 \mathrm{~m} \times 50 \mathrm{~m} \times 10 \mathrm{~m}$ instead of $40 \mathrm{~m} \times 40 \mathrm{~m} \times 10 \mathrm{~m}$, filling the voids of the OBS structure by appropriate rubble material, etc.).

\section{Important Remark:}

A final stability analysis of the OBS foundation should also include the wind loads on the monopile, the rotor wings, and the nacelle as well as their own weights which on the other hand represent stabilizing forces. A very rough estimate of the wind loads on the monopile only has shown that the contribution of the wind loads to the total horizontal force on the OBS structure is generally less than $10 \%$, while the contribution to the total overturning moment may vary from about $40 \%$ to $90 \%$, depending on the water depth considered $(\mathrm{h}=15 \mathrm{~m}$ and $\mathrm{h}=30 \mathrm{~m})$.

The wind loads on the rotor wings and the nacelle will provide a further contribution. However, the consideration of these additional effects which are very complex would require a proper wind engineering expertise and very advanced wind load modelling.

\section{STABILITY OF THE RUBBLE FOUNDATION}

The existing stability formulae such as those proposed by Tanimoto et al. (1982) and by Madrigal and Valdes (1995) have been developed for the rubble foundation of vertical breakwaters (see also USACE, 2002, and CIRIA/CR/CETMEF, 2007, where both formulae are proposed as "standard" design formulae). Applying these formulae for the design wave conditions of the OBS structure with $\mathrm{h}=15 \mathrm{~m}\left(\mathrm{H}_{\mathrm{s}}=7 \mathrm{~m}, \mathrm{~T}_{\mathrm{p}}=11.3 \mathrm{~s}\right)$ and $\mathrm{h}=30 \mathrm{~m}\left(\mathrm{H}_{\mathrm{s}}=10 \mathrm{~m}, \mathrm{~T}_{\mathrm{p}}=17.7 \mathrm{~s}\right)$ rock sizes of $\mathrm{D}_{50}=0.75 \mathrm{~m}$ and $\mathrm{D}_{50}=0.65 \mathrm{~m}$ are respectively obtained by Tanimoto's formula compared to $\mathrm{D}_{50}=0.70 \mathrm{~m}$ and $\mathrm{D}_{50}=0.95 \mathrm{~m}$ according to Madrigal and Valdes' formula. It is obvious that smaller rock sizes would be required for the rubble foundation of the OBS structure, since the aforementioned formulae apply for the rubble foundation of surface piercing, plain vertical structures with very high reflection coefficients. Therefore, hydraulic model tests were conducted to assess the required rock size given the design wave conditions. 
Based on the results of preliminary tests conducted with four different rock sizes $\left(\mathrm{D}_{50} \approx 0.2-1 \mathrm{~m}\right) \mathrm{a}$ rock size $D_{50}=0.26 \mathrm{~m}$ was adopted for the detailed stability tests using more than 7200 irregular waves $\left(\mathrm{H}_{\mathrm{s}}=7-10 \mathrm{~m}, \mathrm{~T}_{\mathrm{p}}=15-18 \mathrm{~s}\right)$ in water depths $\mathrm{h}=15 \mathrm{~m}$ and $\mathrm{h}=30 \mathrm{~m}$. For both water depths, less than 100 stones were displaced corresponding to the "no damage" criterion as defined by Madrigal and Valdes (1995). Since the obtained rock size $D_{50}=0.26 \mathrm{~m}$ is much smaller than those obtained by the aforementioned formulae for vertical breakwaters $\left(D_{50}=0.65-0.95 \mathrm{~m}\right)$ a more detailed analysis of the available knowledge related to the stability of rubble material subject to wave/current was performed to check the reliability of these results. The outcomes of this analysis may be summarized as follows:

(i) Possible scale effects due to the small scale used (1:50)

Based on the results of O'Loughlin et al (1970) who conducted systematic stability tests to quantify scale effects as a function of the grain size related Reynolds number and on the results of Jensen and Klinting (1983) who suggested that Reynolds numbers larger than 104 are locally too high to be used for stability purposes, no correction for scale effects was required for this study.

(ii) Required rock size for rubble foundation/scour protection of 3D-offshore structure

Bos et al. (2002) conducted an interesting study of the scour protection of a GBS (Gravity Based Structure) showing that instead of providing a "static scour protection" a "dynamic scour protection" should be used, this means that a thick layer of smaller sized rock extending to a certain distance of the structure can be used and that scouring of the rock material is allowed as long as the full thickness of the layer is not eroded. In fact such a "dynamic sour protection" might be much more cost effective and can more easily and more rapidly be constructed and maintained using full pipe technology. However, the study of Bos et al (2002) failed to provide any conclusive results on the minimum rock size, layer thickness and extent of scour protection which are required for a "dynamic scour protection".

DenBoon et al. (2004) performed model tests to study scour protection of a monopile in a water depth $\mathrm{h}=24 \mathrm{~m}$ and wave heights of $\mathrm{H}_{\mathrm{s}}=8-10 \mathrm{~m}$ using three stone gradations $(5-40 \mathrm{~kg} ; 10-200 \mathrm{~kg}$; $200-500 \mathrm{~kg}$ ). The results showed that stones were displaced only for the gradation $5-40 \mathrm{~kg}$.

Vos et al. (2006) investigated scour protection of a monopile structure at a scale 1:50 using wave conditions and water depths similar to the present study. They found that stones $\mathrm{D}_{50}=0.26 \mathrm{~m}$ just start to move with a significant wave height $\left(\mathrm{H}_{\mathrm{s}}\right)_{\text {crit. }} \approx 7.5 \mathrm{~m}$. Adding an additional tidal current of $2.5 \mathrm{~m} / \mathrm{s}$ will reduce the critical wave height by more than $25 \%\left(\mathrm{H}_{\mathrm{s}, \text { crit }} \approx 5.5 \mathrm{~m}\right)$.

Based on these outcomes, the results of the present study are in fair agreement with the results of laboratory studies conducted for the scour protection of a monopile in similar water depths and for similar wave conditions. Nevertheless, stones larger than $D=0.26 \mathrm{~m}\left(\mathrm{~m}=50 \mathrm{~kg}\right.$ for $\left.\rho_{\mathrm{s}}=2650 \mathrm{~kg} / \mathrm{m}^{3}\right)$ must be used to avoid any stone displacement ("static scour protection). In fact, it is much more difficult to identify and repair the rubble foundation in deeper water than in shallow water. Thus, the consequences of possible incipient failures may be much more dramatic, if these failures are not identified on time. Moreover, the effect of an additional tidal current may increase the required rock size $\mathrm{D}_{50}$ by more than $30 \%$. The minimum thickness of the armour layer should be equal to three stone sizes $\left(3 \mathrm{D}_{50}\right)$ or at least $2 \mathrm{~m}$. The extent of the armour layer can be estimated as a function of wave height $\mathrm{H}_{\mathrm{s}}$, water depth $\mathrm{h}$ and local wave length $\mathrm{L}_{\mathrm{p}}$ by using the following formula which is similar to the formula commonly used for the scour protection of a rounded head of the rubble mound breakwater:

$$
\mathrm{l}_{\mathrm{s}}=\frac{\mathrm{K}_{\mathrm{s}} \cdot \mathrm{H}_{\mathrm{s}}}{\sinh \left(\frac{2 \pi}{\mathrm{L}_{\mathrm{p}}} \mathrm{h}\right)}
$$

with $\mathrm{K}_{\mathrm{s}}=$ empirical parameter depending on the damage level. Adopting $\mathrm{K}_{\mathrm{s}}=1.0$ and the same design wave conditions as in the present study $l_{\mathrm{s}}=10 \mathrm{~m}$ is obtained fitting well with $1_{\mathrm{s}}=9 \mathrm{~m}$ tested in the model.

\section{CONCLUDING REMARKS}

More than 200 model tests (scale 1.50) conducted in a wave flume to study the wave loads on an OBS structure $(40 \mathrm{~m} \times 40 \mathrm{~m} \times 10 \mathrm{~m})$ made of 16 OB units $(10 \mathrm{~m} \times 10 \mathrm{~m} \times 10 \mathrm{~m})$ and supplemented by sliding stability tests and stability analyses have shown that OBS may indeed be considered as a 
possible new alternative to the traditional types of foundation of offshore wind turbines. Diagrams for the prediction of wave loads on the OBS structure have been derived for two ranges of water depths $(h=15 \mathrm{~m}$ and $\mathrm{h}=30 \mathrm{~m})$. Sliding tests have shown that a static friction coefficient $\mathrm{f}_{\mathrm{R}} \approx 0.6$ can be adopted for the OBS structure on the rubble foundation. The tentative stability analyses, including the effect of wind on the monopile, have shown that the OBS structure is stable against overturning while the safety against sliding needs to be enhanced (e.g. increase the size of the OBS structure or fill the voids in the OBS structure by appropriate rubble material). However, a final stability analysis should necessarily include the additional effect of wind on the rotor wing and on the nacelle which require advanced wind load modelling and a very good wind engineering expertise. Hydraulic model tests for the stability of the rubble foundation and the comparison of the outcomes with the results of previous laboratory tests for scour protection of monopile foundations in similar water depths and for similar wave conditions have shown that armour stones larger than $\mathrm{D}=0.26 \mathrm{~m}$ and an armour layer thickness of $3 \mathrm{D}_{50}$ (at least $2 \mathrm{~m}$ ) with an extent of about $10 \mathrm{~m}$ would be required.

\section{ACKNOWLEDGMENTS}

The authors would like to thank Mr. Richard Scheiner, Consultant Engineer OB System, for the preparation of the T.O.R. for tests and OBS Ltd. for providing the Oceanbricks (patented) models (www.oceanbricks.com).

\section{REFERENCES}

Bos, K.J.; Verheij, H.J.; Kant, G. and A.C.H. Kruisbrink. 2002. Scour protection around gravity based structures using small size Rock. First International Conference on Scour of Foundations, Texas University, College Station, Texas, USA, pp. 567-581.

CIRIA/CUR/CETMEF. 2007. The Rock Manual. The use of rock in hydraulic engineering. CIRIA / CUR, CIRIA C683, 2nd edition, London, 1236 p.

DenBoon, J.H.; Sutherland, J.; Whitehouse, R.J.S.; Soulsby, R.; Stam, C.J.; Verhoeven, K.; Hoegedal, M. and T. Hald, T. 2004. Scour behaviour and scour protection for monopile foundations of offshore wind turbines. Proc. EWEC.

Jensen, O.J. and P. Klinting. 1983. Evaluation of scale effects in hydraulic models by analysis of laminar and turbulent flows. Amsterdam, The Netherlands: Elsevier, Coastal Engineering, vol. 7, pp. 319-329.

Madrigal, B.G. and J.M. Valdés. 1995. Study of rubble mound foundation stability. Proceedings Final Project Workshop, MAST II, MCS-Project: Monolithic (Vertical) Coastal Structures, Alderney, U.K., 38 p.

O'Loughlin, E.M.; Mehrotra, S.C.; Chang, C. and J.F. Kennedy. 1970. Scale effects in hydraulic model tests of rock protected structures. IHHR Report No. 24, Iowa University, 37p.

Oumeraci, H. (2009). Non-conventional wave damping structures. Handbook of Coastal and Ocean Engineering. P. Y. C. Kim. USA, World Scientific Publishing: 34 p., in print.

Oumeraci, H.; Pfoertner, S.; Kudella, M. and A. Kortenhaus. 2008. Ocean Brick System (OBS) in a Wave Flume - Part I: A Foundation Structure for Offshore Wind Turbine. LWI Report No. 972, Leichtweiss-Institute, pp. $73+3$ annexes.

Tanimoto, K.; Yaghu, T. and Y. Goda. 1982. Irregular wave tests for composite breakwater foundation. Proceedings 18th International Conference Coastal Engineering (ICCE), ASCE, Volume 3, Capetown, South Africa, pp. 2144-2163.

USACE. 2002. Coastal Engineering Manual. Engineer Manual 1110-2-1100, US Army Corps of Engineers, Washington D.C., USA (in 6 volumes).

Vos, L.D.; De Rouck, J. and P. Troch. 2006. Design of scour protection around offshore monopiles under combined wave and current loading. Pro. OWEMES. 